\title{
АНАЛИЗ ПОДХОДОВ К ОЦЕНКЕ ИНВЕСТИЦИОННОЙ ПРИВЛЕКАТЕЛЬНОСТИ РЕГИОНА (НА ПРИМЕРЕ РОСТОВСКОЙ ОБЛАСТИ)
}

\author{
(c) 2021 Янченко Дмитрий Валерьевич \\ кандидат технических наук, доцент, доцент кафедры менеджмента \\ Новочеркасский инженерно-мелиоративный институт им. А. К. Кортунова - \\ филиал Донского государственного аграрного университета, Россия, Новочеркасск \\ E-mail:Yn70@mail.ru
}

\section{(C) 2021 Чернышова Татьяна Николаевна}

магистрант

Южно-Российский государственный политехнический университет (НПИ) имени М.И.Платова, Россия, Новочеркасск

E-mail: Tatiana88n@gmail.com

\section{(c) 2021 Васькина Валентина Николаевна}

магистрант

Южно-Российский государственный политехнический университет (НПИ) имени М.И. Платова, Россия, Новочеркасск

E-mail: valentinka_856@mail.ru

\section{(c) 2021 Ковязо Екатерина Альбертовна}

магистрант

Южно-Российский государственный политехнический университет (НПИ) имени М.И. Платова,

Россия, Новочеркасск

E-mail: kovyaso_ekaterina@mail.ru

В статье рассматриваются основные расчётно-аналитические инструменты оценки инвестиционного потенциала на мезоэкономическом уровне, анализируются их преимущества и недостатки, представлена прогнозная динамика инвестиционного потенциала Ростовской области, обоснованы организационно-экономические и административные направления повышения инвестиционной привлекательности региона.

Ключевые слова: инвестиции, регион, экономика, развитие, Ростовская область, организационноэкономические мероприятия.

На современном этапе одной из приоритетныхзадачуспешногосоциально-экономического развития российских регионов является всемерное развитие инвестиционного потенциала за счёт формирования благоприятной для капиталовложений экономико-административной среды. Указанные обстоятельства в полной мере аргументируют актуальность и своевременность научных работ, направленных на исследование расчётно-аналитических инструментов идентификации факторов формирования и оценки инвестиционной привлекательности на мезоэкономическом уровне.

Оценить региональный потенциал региона можно при помощи различных методов, схожих, однако, всеобъемлющим охватом объекта оценки. Так как инвестиционный потенциал региона зависит от многих составляющих, так и оценивается он с позиции оценки этих составляющих [2]. В качестве таких составляющих можно отметить:

- разнообразные природные характеристики, такие как географическое положение, наличие природных объектов (гор, рек, лесов, степей), полезных ископаемых, что формирует ресурсно-сырьевой фактор;

- степень развития реальной экономики в регионе, что формирует производственный фактор;

- потребительский фактор складывается из уровня состоятельности населения, среднего уровня заработной платы в регионе, что обеспечивает определенный уровень покупательной способности; 
- инфраструктурный, институциональный и инновационный факторы, отражающие транспортную, институциональную, ресурсную и иную обустроенность территории, уровень развития науки и внедрения научно-технических достижений;

- интеллектуальный и трудовой факторы, формирующиеся исходя из численности и доли трудоспособных и образованных граждан в общей численности населения региона.

Методики оценки инвестиционного потенциала разрабатывались как в России, так и за рубежом. Расчётно-аналитических инструментов оценки инвестиционного потенциала достаточно много, причем способы оценки также достаточно разнообразны. В одних методиках используются балльные шкалы, в других экспертные методы, третьи основаны на статистических данных и имеют под собой реальную основу в виде конкретного числового материала. Следует отметить, что некоторые составляющие инвестиционного потенциала достаточно сложно привязать к каким-то количественным оценкам, вследствие чего требуется качественный подход, реализуемый, в основном, посредством систематизации экспертных оценок по заданным целями исследования критериям.

Авторами предлагается сгруппировать наиболее часто используемые методики оценки инвестиционного потенциала в три группы:

1. Методики, основывающиеся на экономико-математических методах;

2. Методики, основывающиеся на факторном анализе;

3. Методики, основывающиеся на экспертных оценках.

Первая группа представлена следующими основными методиками оценки инвестиционного потенциала региона:

Метод суммы мест. Данная методика предполагает ранжирование регионов по каждому критерию, влияющему на общий инвестиционный потенциал региона. Соответственно, тот регион, который является лидирующим по большинству позиций, считается наиболее привлекательным или обладающим наивысшим потенциалом для инвесторов.

Метод балльных оценок. Расчётноаналитический аппарат данного метода имеет некоторое сходство с методом суммы мест, с той лишь разницей, что в данном случае характеристики, складывающиеся в общий инвестицион- ный потенциал, оцениваются в баллах, что в свою очередь повышает риск искажения результатов оценки за счёт влияния субъективных факторов. В тоже время, метод балльных оценок сравнительно прост, универсален, нагляден и доступен, что является его достоинством и недостатком одновременно, так как влияет на степень достоверности результатов, особенно в случае применения органами государственной власти субъектов РФ для самостоятельной оценки результатов своей деятельности по каким-либо направлениям социально-экономического развития.

Метод многомерной средней. При применении данного метода оценки сравнение производится со средними величинами по Российской Федерации. Таким образом, каждый параметр при сравнении может быть оценен конкретным коэффициентом, на основе которых затем исчисляется интегрированный показатель. Одним из важнейших преимуществ данного метода является минимизация влияния субъективных факторов при осуществлении оценки.

Метод «Паттерн». В данном случае, в отличие от предыдущего, сравнение производится не со средним, а с максимальным показателем, что определяет для регионов уровень, к которому необходимо стремиться.

Рассмотренные в первой группе методы достаточно примитивны и просты, что обеспечило им широкое распространение. В то же время сомнительной считается обоснованность некоторых моментов, таких как: включение того или иного параметра в перечень, степень важности или весомости включенных параметров, применение экспертных оценок и т.п.

Методы, основанные на факторном анализе, не менее востребованы при оценке инвестиционной привлекательности на мезоэкомическом уровне, чем остальные. Преимуществом факторного анализа является возможность оценки не только результирующего показателя, в данном случае инвестиционного потенциала, но и влияние на результат каждого из составляющих его факторов. Такая информация позволяет объективно трактовать причины позитивных или негативных тенденций, своевременно вырабатывать действенные корректирующие мероприятия. В данном случае, в группе факторного анализа применяют два основных расчётно-аналитических инструмента: факторные модели и регрессионный анализ. Регрессионный анализ позволяет исчислить ко- 
личественную степень воздействия каждого составляющего фактора на результат посредством определение веса данного фактора. Факторное моделирование предполагает исследование взаимосвязей определяющих результат факторов.

Любое явление вместе с показателями, его описывающими, является результатом лежащих в его основе различных причин, на исследование которых направлен факторный анализ. Этот метод позволяет определить наиболее значимые или весомые факторы, воздействующие на результат.

Метод экспертных оценок в настоящее время пользуется популярностью и часто применяется в силу относительной простоты использования. Этот инструмент показывает высокую эффективность при поддержке его факторным анализом и исчислением средних значений количественных показателей, характеризующих объект исследования.

Вышеизложенные методы оценки позволяют сгруппировать и ранжировать регионы страны, составить их рейтинг от наиболее интересного для инвесторов к наименее интересному. При необходимости получения наиболее достоверной оценки необходимо использовать несколько методов, дающих в результате комплексную оценку, позволяющую повысить эффективность деятельности как владельцев капитала, так и органов государственной власти субъектов РФ, реализующих экономическую политику.

Так как большинство расчётно-аналитических инструментов оценки инвестиционной привлекательности на мезоэкономическом уровне используют некоторые существующие количественные данные, то на основе этих оценок может быть спрогнозировано и спланировано дальнейшее развитие региона не только в инвестиционном, но и в инновационном аспектах.

C учётом концептуально-теоретических положений вышеизложенных методик, осуществим расчёт прогнозных значений инвестиционной привлекательности различных отраслей экономики Ростовской области. Эмпирической основой расчётов являются данные территориального управления Росстата [6], правительства Ростовской области [5], экспертных оценок представителей научного сообщества региона [1, $2,4,7]$.

Уровень производственного потенциала является одним из факторов, детерминирую- щих валовой региональный продукт. Запланированный федеральными и региональными нормативно-правовыми актами комплекс мероприятий направлен на стимулирование развития основных отраслей, формирующих экономику Ростовской области. Предположим, что объём инвестиций в основной капитал повлияет на валовой региональный продукт пропорционально.

Показателями, формирующими трудовой потенциал, являются численность занятого в экономике населения, продолжительность жизни и количество студентов вузов. На трудовом потенциале положительно отражаются социально-направленные мероприятия, реализуемые в рамках реализации государственной социально-экономической политики РФ и Ростовской области, и связанные, в том числе, с повышением уровня компетенции работников, производительности труда, однако в ближайшие годы указанные мероприятия на составляющих трудового потенциала отразятся очень незначительно, так как эти мероприятия направлены на долгосрочную перспективу. По мнению экспертов, рост трудового потенциала не превысит 0,1\% в первые 5 лет после реализации мероприятий, 0,5\% - в первые 10 лет и 5\% - в ближайшие 15 лет. В дальнейшем рост будет происходить в затухающей геометрической прогрессии.

Если предположить, что потребительский, финансовый и инновационный потенциалы региона зависят от уровня валового регионального продукта и, следовательно, производственного потенциала пропорционально, то можно рассчитать уровень потребительского, финансового и инновационного потенциала.

Инфраструктурный потенциал Ростовской области не слишком высок, но ожидать его значительного изменения в ближайшей перспективе не стоит, так как лидер - Краснодарский край, по этому направлению значительно опережает Ростовскую область. Природно-ресурсный и туристический потенциалы Ростовской области не изменятся под влиянием реализуемых в настоящее время мероприятий государственной социально-экономической политики региона.

Рассмотрим влияние вышеизложенных факторов в контексте динамики инвестиционного потенциала Ростовской области (таблица $1[5,7])$.

Анализ информации, представленной в таблице 1 показывает, что прогнозное значение суммарного инвестиционного потенциала Ро- 
Таблица 1. Прогнозная динамика инвестиционного потенциала Ростовской области

\begin{tabular}{|c|c|c|c|c|c|c|c|}
\hline \multirow[b]{2}{*}{ Наименование показателя } & \multirow{2}{*}{$\begin{array}{c}2020 \text { год, } \\
\text { млрд. } \\
\text { руб. }\end{array}$} & \multirow{2}{*}{$\begin{array}{c}\text { Прогноз- } \\
\text { ный темп } \\
\text { роста, \% }\end{array}$} & \multirow{2}{*}{$\begin{array}{c}2023 \text { год, } \\
\text { млрд. } \\
\text { руб. }\end{array}$} & \multirow{2}{*}{$\begin{array}{c}\text { Прогноз- } \\
\text { ный темп } \\
\text { роста, \% }\end{array}$} & \multirow{2}{*}{$\begin{array}{c}2025 \text { год, } \\
\text { млрд. } \\
\text { руб. }\end{array}$} & \multicolumn{2}{|c|}{ Динамика } \\
\hline & & & & & & $\begin{array}{l}\text { млрд. } \\
\text { руб. }\end{array}$ & $\%$ \\
\hline 1. Производственный потенциал & 63,7 & 8,6 & 69,2 & 109,2 & 75,6 & 11,9 & 18,7 \\
\hline 2. Трудовой потенциал & 62,7 & 0,1 & 62,8 & 100,5 & 63,0 & 0,3 & 0,5 \\
\hline 3. Потребительский потенциал & 60,0 & 8,6 & 65,1 & 109,2 & 65,5 & 5,6 & 9,3 \\
\hline 4. Инфраструктурный потенциал & 39,9 & 0,0 & 39,9 & 100,0 & 39,9 & 0,0 & 0,0 \\
\hline 5. Финансовый потенциал & 24,8 & 8,6 & 26,9 & 109,2 & 27,1 & 2,3 & 9,3 \\
\hline 6. Инновационный потенциал & 42,2 & 8,6 & 45,9 & 109,2 & 46,1 & 3,9 & 9,2 \\
\hline 7. Природно-ресурсный потенциал & 13,2 & 0,0 & 13,2 & 100,0 & 13,2 & 0,0 & 0,0 \\
\hline 8. Туристический потенциал & 36,0 & 0,0 & 36,0 & 100,0 & 36,0 & 0,0 & 0,0 \\
\hline $\begin{array}{l}\text { Суммарный инвестиционный } \\
\text { потенциал региона }\end{array}$ & 342,5 & 4,8 & 359,0 & 107,0 & 366,4 & 23,9 & 7,0 \\
\hline
\end{tabular}

стовской области демонстрирует рост с 342,5 млрд. руб. в 2020 г. до 366,4 млрд. руб. в 2025 г. (+23,9 млрд. руб., +7,0\%). Подобная тенденция, по нашему мнению, будет обусловлена действием следующих факторов: восстановлением платёжеспособного спроса граждан; развитием цифрового сегмента экономки крупнейшей на Юге России Ростовской-на-Дону агломерации; формированием новой отрасли экономики, связанной с производством энергии за счёт возобновляемых источников (поэтапная реализация проекта строительства ветропарка в районе г. Каменса [5]).

Подводя итог сказанному, сформулируем следующие основные выводы:

1. В настоящее время Ростовская область представляет собой один из крупнейших регионов Юга России, обладающих развитой промышленностью, агропромышленным комплексом, транспортно-логистической инфраструктурой. Среди конкурентных преимуществ региона необходимо выделить: наличие границы с иностранным государством, наличие выхода к Азовскому морю, наличие судоходной реки Дон, пригодной для плавания судов класса «река-мо- ре», благоприятные природно-климатические условия, позволяющие осуществлять экономически эффективную сельскохозяйственную деятельность (главным образом, в сфере растениеводства) [3, 4];

2. Успешная реализация инвестиционного потенциала Ростовской области подразумевает формирование на микро- и мезоэкономическом уровнях благоприятной среды, привлекательной для капиталовложений. Регионы Российской Федерации, в целом, и Ростовская область, в частности, располагают полномочиями по формированию административных, бюджетных, налоговых стимулов, побуждающих инвесторов к капиталовложениям. По нашему мнению, элементами подобного механизма могут быть налоговые преференции, в виде сниженных ставок по региональным налогам (дифференцированным в зависимости от критериев, задаваемых приоритетами региональной экономической политики), а также отсрочки по уплате некоторых видов региональных налогов и сборов для инвесторов, реализующих проекты на территории Ростовской области в приоритетных отраслях экономики.

\section{Библиографический список}

1. Горбанёва О.И. Динамическая сочи-модель регионального развития: сравнительный анализ административных и экономических механизмов управления (на примере Южного федерального округа) / Горбанева О.И., Мурзин А.Д., Угольницкий Г.А. // Математическая теория игр и ее приложения. 2021. Т. 13. № 1. С. 59-88.

2. Москаленко А.П. Инвестиционное проектирование: основы теории и практики / Москаленко А.П., Москаленко С.А., Ревунов Р.В., Вильдяева Н.И. // Санкт-Петербург, 2018. (1-е, Новое)

3. Ревунов Р. В. Повышение эффективности экономического комплекса Юга России / Ревунов Р. В., Дальченко Е.А. // Императивы, векторы, организационно-экономические решения / Саарбрюкен, 2016. 
4. Ревунов Р.В. Направления повышения эффективности сельского хозяйства Ростовской области / Ревунов Р.В., Ревунов С. В., Шереметьев П. Г., Чернышова Т. Н. // Московский экономический журнал. 2021. № 6.

5. Официальный сайт Правительства Ростовской области https:/www.donland.ru/activity/108/ дата обращения 5 октября 2021 г.

6. фициальный сайт управления Росстата по Ростовской области https://rostov.gks.ru/statistic дата обращения 5 октября 2021 г.

7. Anopchenko T. Yu. Vectors of increasing the efficiency of the modern economy of the region (based on the materials of the Rostov region) / Anopchenko T.Yu., Revunov R.V., Murzina S.M., Gubachev V.A., Dalchenko E.A. // B сборнике: Modern Global Economic System: Evolutional Development vs. Revolutionary Leap. Lecture Notes in Networks and Systems (LNNS, Volume 198). Cham, 2021. C. 2163-2169. 